\title{
Imobiliário-Infraestrutura na cidade do século XXI: desafios para uma crítica contra-hegemônica
}

\author{
Luciana Nicolau Ferrara, Maria Beatriz Cruz Rufino, \\ Lucia Zanin Shimbo*
}

Resumo A produção do espaço urbano se alterou profundamente e o domínio da financeirização impõe novos desafios analíticos para a compreensão dos fenômenos em curso. O objetivo deste artigo é problematizar conceitos relacionados à interpretação da urbanização contemporânea que, de certo modo, ocultam as relações sociais, as formas de espoliação e a reprodução de desigualdades. Trata-se de uma análise dos debates ocorridos na Escola de Ciência Avançada "Produção Imobiliária: desigualdade, financiamento e planejamento territorial na América Latina" ocorrida em 2017 na Universidade de São Paulo e que reuniu pesquisadores do Brasil, Chile, Argentina, Venezuela e México, associada a uma revisão bibliográfica dos principais estudos latino-americanos sobre produção imobiliária e infraestrutura urbana.

Palavras-chave: urbanización, expoliación, financiarización.

\section{Inmobiliario-Infraestructura en la ciudad del siglo XXI: desafíos para una crítica contra- hegemónica}

\begin{abstract}
Resumen La producción del espacio urbano se alteró profundamente y el dominio de la financiarización impone nuevos desafíos analíticos para la comprensión de los fenómenos en curso. El objetivo de este artículo es problematizar conceptos relacionados a la interpretación de la urbanización contemporánea que, en cierto modo, ocultan las relaciones sociales, las formas de expoliación y la reproducción de desigualdades. Se trata de un análisis de los debates ocurridos en la Escuela de Ciencia Avanzada "Producción inmobiliaria e infraestructura: desigualdad, financiamiento y planificación territorial en América Latina" ocurrida en 2017 en la Universidad de São Paulo y que reunió investigadores de Brasil, Chile, Argentina, Venezuela y México, asociada a una revisión bibliográfica de los principales estudios latinoamericanos sobre producción inmobiliaria e infraestructura urbana.
\end{abstract}

Palabras clave: urbanização, espoliação, financeirização.

\section{Real Estate-Infrastructure in the city of 21st century: challenges for a counter hegemo- nic critique}

\begin{abstract}
The production of urban space has deeply changed and the dominance of financialization imposes new analytical challenges to understand the ongoing phenomena. The purpose of this paper is to discuss the concepts related to the interpretation of contemporary urbanization that, in a way, hide social relations, forms of dispossession and reproduction of inequalities. This is an analysis of the debates occurred at the School of Advanced Science "Real estate and infrastructure: inequality, financing and territorial planning in Latin America" held in 2017 at the University of São Paulo and which brought together researchers from Brazil, Chile, Argentina, Venezuela and Mexico. It also associates a bibliographical review of the main Latin American studies on real estate and urban infrastructure.
\end{abstract}

Keywords: urbanization, dispossession, financialization. 
1 Não cabe aqui uma revisão da bibliografia, mas vale lembrar uma problematização desse conhecimento apresentada em Pereira et al (1991).

* Luciana Nicolau Ferrara é Arquiteta e Urbanista, professora da Universidade Federal do $A B C$, SP, Brasil,ORCID <http://orcid. org/0000-0002-0493-376X> Maria Beatriz Cruz Rufino é Arquiteta e Urbanista, professora da Faculdade de Arquitetura e Urbanismo da Universidade de São Paulo, SP, Brasil, ORCID <http://orcid.org/0000-00020063-0059>; Lucia Zanin Shimbo é Arquiteta e Urbanista, professora do Instituto de Arquitetura e Urbanismo da Universidade de São Paulo, SP, Brasil. ORCID <http://orcid.org/0000-00021097-8091>. produção do ambiente construído mostra-se ainda pouco conhecida frente à sua importância política, econômica e social sendo objeto de controvérsias que estão a merecer avanços inovadores em seus estudos e pesquisas' ${ }^{1}$. A intensificação da produção imobiliária e a expansão dos investimentos em infraestrutura evidenciadas nas cidades latino-americanas no século XXI, além de reforçarem a importância dessas atividades para a compreensão das mudanças urbanas e territoriais mais amplas, têm indicado uma crescente articulação entre os ramos e setores, impondo novos desafios para o planejamento territorial e urbana e para a interpretação crítica da produção do espaço.

Um aspecto a se considerar é a profunda articulação de processos mais imediatos de produção do espaço (como a própria atividade da construção civil), verificados em nossas cidades, com processos globais, oriundos de uma reestruturação capitalista, que implica, em última instância, em mudanças radicais na totalidade das relações sociais. Pode-se afirmar que esse quadro de intensificação da produção imobiliária e de modernização seletiva de infraestruturas relaciona-se com a consolidação de um capitalismo dominado pelas finanças (CHESNAIS, 2005; HARVEY, 2005; LAPAVITSAS, 2013) e apoiado em Estados neoliberais (LAVAL, DARDOT, 2017; HARVEY, 2008).

Lefebvre (2008 [1970]) em seu texto A Revolução Urbana, ao problematizar a emergência de uma sociedade urbana, chama atenção para um aspecto novo da produção do espaço - sua produção global e total. Essa produção se dá, então, em função de interesses globais, que passa também a alterar o próprio sentido desse espaço como totalidade, interferindo até mesmo na vida cotidiana. Para Lefebvre (2008 [1970]):

A produção do espaço, em si, não é nova. Os grupos dominantes sempre produziram este ou aquele espaço particular, o das antigas cidades, o dos campos (aí incluídas as paisagens que em seguida parecem "naturais"). O novo é a produção global e total do espaço social. Essa extensão enorme da atividade produtiva realiza-se em função dos interesses dos que a inventam, dos que a gerem, dos que dela se beneficiam. (...) Essa estratégia oprime o "usuário", o "participante", o simples "habitante". Ele é reduzido não apenas a função do habitar (ao habitat como função), mas a função de comprador de espaço, realizando mais valia. (LEFEBVRE, 2008 [1970]:141)

Para o autor, o capitalismo encontrou na produção do espaço um alento a suas crises, que passou a ter papel determinante na formação, realização e distribuição da mais valia global. Essa percepção, desenvolvida ainda nos anos 1970, toma força ainda maior no contexto da financeirização.

Dentre as principais tendências no debate sobre financeirização, que envolvem entendêla como um regime de acumulação, como colonização de instituições ou ainda como submissão do cotidiano às finanças (endividamento), consideramos financeirização o processo de ampliação do domínio do capital financeiro na economia alcançado pelo seu crescente deslocamento da função de credor para proprietário situado em 
2 Os participantes de cada um dos grupos de trabalho são apresentados no Anexo desse artigo. Agradecemos a grande contribuição de todos no debate. O evento foi realizado em maio de 2017 na FAUUSP. situação de exterioridade à produção (CHESNAIS, 2005). Como proprietário, este capital tem como expectativa de direito a uma renda e se deslocará no sentido dos ativos financeiros que the proporcionarem maiores rendimentos. $O$ deslocamento do capital financeiro à produção do espaço nessa nova posição de proprietário, seja via fundos de investimentos, ações de empresas ou securitização de dívidas, entre outras formas, torna mais evidente a necessidade de articulação dos processos globais à produção imediata do ambiente construído.

Como parte da transformação da produção do ambiente construído em diferentes níveis e dimensões é preciso avançar no debate sobre a reprodução do cotidiano e as implicações sociais desse processo que é espoliativo e tende a aprofundar desigualdades socioespaciais na vida das pessoas e nas condições materiais de reprodução social, o que inclui a transformação da natureza. Nesse sentido, a dimensão da totalidade desse processo, ainda que não seja evidente, não pode ser desconsiderada.

Essa percepção inicial motivou a realização da Escola de Ciência Avançada "Produção imobiliária e infraestrutura: desigualdade, financiamento e planejamento territorial na América Latina" que, além das conferências, se estruturou em grupos de trabalho em torno da ênfase em três temas², constituídos como eixos de interlocução: política, produção e espaço. Tal divisão procurou dar conta da complexidade dos temas, ao enfrentar questões teóricas e de método, problematizar diferentes níveis e dimensões de análises e aproximar distintas abordagens disciplinares, considerando o contexto e as especificidades da urbanização latino-americana.

No eixo política, que tinha como objetivo debater a ação do Estado e o papel do planejamento territorial, emergiram temas como as formas de regulamentação e a sofisticação das formas de propriedade e de consumo. Os debates em torno desses temas evidenciaram as limitações dos mesmos ao naturalizar o crescente papel do estado regulador, obscurecendo novas relações sociais de dominação impostas no curso da produção das políticas. O eixo produção partiu das dimensões da construção e das relações de trabalho no canteiro de obras, que envolve diferentes objetos empíricos que perpassam a construção do ambiente construído: habitação, equipamentos públicos, imóveis e também os diferentes tipos de infraestrutura, (redes de saneamento, energia, transporte e mobilidade, telecomunicações, loteamentos). O eixo espaço partiu da materialidade do espaço como reveladora de relações sociais, considerando o lugar da natureza (terra e propriedade privada) no processo de reprodução do espaço. Os novos arranjos entre os atores (eixo política) e as formas de produção (eixo produção) mobilizam a propriedade privada da terra, potencializam a exploração da natureza e colocam a necessidade de se compreender as formas de extração de rendas envolvidas na produção imobiliária e de infraestruturas, em diferentes escalas.

Em seu conjunto, os debates mostraram que as transformações globais no capitalismo têm produzido novas articulações entre agentes públicos e privados na produção do espaço gerando consequências sociais e ambientais que já não podem mais ser explicadas a partir da interpretação da urbanização industrial, ainda que haja permanências e descontinuidades nesse processo. A realidade urbana das cidades latino-americanas se insere no contexto do circuito internacional de capitais com suas especificidades, o que requer a elaboração de teorias e interpretações próprias. 
O presente artigo traz as discussões mais importantes ocorridas no Evento e que foram em seguida elaboradas pelas autoras. O objetivo é problematizar abordagens e categorias de análise utilizadas para a interpretação da urbanização contemporânea buscando evidenciar de que modo são ocultadas relações sociais consideradas centrais para a crítica da produção do espaço e das formas de espoliação urbana.

O texto estrutura-se em duas partes principais. Na primeira, são problematizadas abordagens e categorias teórico-metodológicas que, na nossa visão, têm se apresentado como obstáculo para a interpretação crítica dos processos hegemônicos em curso. Trata-se de questionar a fragmentação ainda persistente entre a produção imobiliária e de infraestrutura, a interpretação baseada na divisão entre processos formais e informais de produção do espaço, e o papel da natureza na transição da dominância industrial para financeira, e como parte da produção da metrópole. Na segunda parte do texto, procuramos esboçar elementos de uma agenda de pesquisa que supere tais fragmentações, considerando os avanços alcançados com a realização do Evento.

\section{Conceitos em debate}

\section{Separação entre imobiliário e infraestrutura}

O setor da construção historicamente diferenciou-se em dois grandes segmentos: a produção de obras civis (ou de infraestruturas) e a produção de edifícios (residenciais e não residenciais). Essa segmentação deu lugar a dinâmicas e ramos independentes, tal como se sucedeu na evolução de outros setores econômicos com múltiplos vasos comunicantes (como por exemplo, a indústria têxtil e de confecção), fazendo com que a construção albergue em seu seio uma grande variedade de produtos pertencentes a um mesmo ramo (LOVERA, 2011).

Como reflexo da relevância dessa atividade para a produção do espaço e de sua intrínseca relação com a cidade e o território, as atividades de construção pesada (ou de infraestruturas) e de incorporação (ou imobiliária) têm sido objeto de estudo das mais variadas disciplinas, com flutuações expressivas quanto à sua representatividade enquanto campo de pesquisa e à constituição de um corpo científico capaz de articular as diferentes dimensões e níveis de abordagens que implicam o seu adequado conhecimento.

Na Classificação Nacional das Atividades Econômicas (CNAE) definida pelo Instituto Brasileiro de Geografia e Estatística (IBGE), a seção da construção é formada por três divisões: construção de edifícios, obras de infraestrutura e serviços especializados para a construção. A construção de edifícios engloba as atividades de incorporação imobiliária e a construção de edifícios propriamente dita. As obras de infraestrutura referem-se aos equipamentos públicos urbanos, transporte, energia e saneamento, além de obras industriais. E os serviços especializados para construção são relacionados às atividades-meio para a execução das obras como, por exemplo, terraplanagem, instalações diversas, acabamento e fundações.

Diversas denominações já foram adotadas no debate acadêmico, como por exemplo, "ramo" (filière, em francês, mas que não tem uma correspondência exata para o português, CARASSUS, 1987); "macrocomplexo da construção" (PROCHNIK, 1987); 
construbusiness - bastante adotada pelos agentes do próprio setor; e "sistema produtivo setorial" (BOUGRAIN, CARASSUS, 2003).

Ao denominar o "ambiente construído" como a "totalidade das estruturas físicas casas, ruas, fábricas, escritórios, sistemas de esgotos, parques, equipamentos culturais e educacionais etc." , Harvey (1982) procurou unificar esses setores que comumente se encontram separados, tanto do ponto de vista econômico quanto como objeto empírico dos estudos urbanos. Harvey (1982, p. 6) argumenta que a sociedade capitalista precisa criar "uma paisagem física - uma massa de recursos físicos construídos pelo homem à sua própria imagem, apropriada, em linhas gerais, às finalidades da produção e do consumo" e que esse processo de criação é cheio de contradições e tensões.

Consoante com a noção de Harvey, Lovera (2014) chama de "cadeia produtiva da construção", considerando que a construção é composta por atividades técnicoconstrutivas e por atividades econômicas cujo objeto final é o "meio ambiente construído", envolvendo edificações e obras civis e considerado como suporte físico para a reprodução da sociedade.

Gitahy e Pereira (2002) pensaram num "complexo industrial da construção" quando a habitação econômica passou a ser um nicho de mercado no Brasil dos anos 1930, e se inspiraram na matriz econômica que pensou a formação do "complexo cafeeiro" para a escolha do termo. Mais do que um único capital ou agente ou segmento, trata-se de um "complexo" que abrange todas as atividades relacionadas à produção da habitação: concepção, planejamento, aquisição de terras, construção, regulação, financiamento, distribuição e manutenção.

Mais recente e internacionalmente, diante dos processos mais gerais de financeirização da economia, os vínculos entre mercado imobiliário e finanças se estreitaram e Aalbers (2015) vai denominar, portanto, a noção de "complexo imobiliário/financeiro" (real estate/financial complex).

A denominação "complexo" ganha força na medida que reforça a adequada ideia de interdependência dessas várias atividades e entre as várias empresas e instituições que as promovem, tanto do ponto de vista técnico, quanto político e econômico. Na apropriação do termo "complexo" para explicar as dinâmicas da produção do espaço em dois contextos históricos diferentes, chamamos atenção para um deslocamento do processo de acumulação "industrial" (produtivo) para o "financeiro" (rentista e especulativo).

A relevância dos processos globais na produção do espaço, expressos pela crescente mobilização do conceito de financeirização, não pode ocultar especificidades estruturais nas relações de produção, negligenciadas do ponto de vista histórico pelo predomínio de uma visão industrial.

Ao mesmo tempo, o imbricamento entre imobiliário e infraestrutura nos provoca a repensar as infraestruturas como condições gerais, na medida em que, conforme formulado por Marx, articulam o consumo produtivo (consumo coletivo) ao processo de produção e circulação do capital (LENCIONI, 2007). No contexto da financeirização do urbano, com intervenções que promovem a diferenciação dos espaços, as infraestruturas 


\footnotetext{
${ }^{3} \mathrm{~A}$ fragmentação das unidades em termos de tempo pode ser vista, por exemplo, nos esquemas de timeshares, em que os proprietários adquirem em seus contratos a propriedade de períodos de tempo determinados.

${ }^{4}$ A mais relevante forma de fragmentação física das propriedades se concretiza pelos Fundos de Investimento Imobiliários.
}

públicas além de serem capturadas e centralizadas para a valorização imobiliária, são concebidas, elas mesmas, por uma lógica privatista e rentista.

Diferente das demais mercadorias, o imobiliário tem imbricado em si a propriedade privada. Aos proprietários de terra cabe a disputa sobre uma parte da mais-valia da atividade de construção na forma de renda imobiliária (RUFINO, 2017). Para Pereira, "a renda imobiliária provém do caráter de monopólio de privatização do espaço que, pela necessidade de se pagar o acesso à localização, torna possível a formação de um preço de mercado imobiliário que sobe até os limites permitidos pelas condições de pagamento na disputa pela utilização do espaço" (PEREIRA, 1984, p. 245). Pela existência da renda, legitimada pela relação da propriedade privada, toda vez que se fazem investimentos na produção da cidade, há implicações na valorização da propriedade imobiliária urbana (SEABRA, 1986).

A relação entre imobiliário e infraestrutura é em grande medida ocultada pelo predomínio de uma visão industrial na leitura das dinâmicas urbanas, que desconsiderando as especificidades da produção do espaço, negou o papel crescente da propriedade privada da terra e do imobiliário para a reprodução do capital. A propriedade privada da terra e dos imóveis assegura aos proprietários importantes processos de capitalização, em grande medida, relacionados aos desiguais investimentos de infraestruturas na metrópole. Nesse sentido, parece importante enfatizar que a indústria da construção se consolida cada vez mais como uma indústria de propriedade, em que construção e terra são indissociáveis. Essa indissociabilidade não impede a multiplicação de possibilidades de fragmentação dessa mesma propriedade no tempo ${ }^{3}$ e no espaço ${ }^{4}$. processo que poderia ser reconhecido como uma "desabsolutização da propriedade", num movimento de crescente potencialização da renda imobiliária (PEREIRA, 2005).

Com a expansão da financeirização, ficou evidente o alcance de novos patamares de investimentos na produção do espaço, evidenciados no imobiliário, nas infraestruturas e nos esforços de coordenação entre os mesmos. Essas transformações têm dado maior relevância à captura de renda imobiliária como parte substancial dos ganhos envolvidos na produção do espaço. No atual contexto da predominância do capital financeiro, trabalhamos com a hipótese de que o que articula o imobiliário e a infraestrutura é o objetivo de capturas de rendas imobiliárias, o que implica em mobilizar a terra em diversas formas de propriedade, como os títulos mobiliários deles derivados. A crescente relevância de captura de renda imobiliária articula-se em um nível global com grande quantidade de capital financeiro que busca se rentabilizar.

Em termos empíricos, o imbricamento entre imobiliário e infraestrutura aparecerá tanto na emergência de bairros planejados para diferentes estratos sociais em áreas pouco infraestruturadas, como nos processos de reestruturação urbana, viabilizados em grande medida por instrumentos baseados em parcerias público-privadas e pautados na modernização seletiva de infraestruturas.

Uma marca geral desse processo, que aproxima vários países da América Latina, foi a produção massiva de habitação popular a partir de políticas públicas. Poderíamos citar o Programa Minha Casa Minha Vida no Brasil e as precursoras políticas habitacionais do Chile e México. Como parte dessas políticas emergiram grandes complexos habitacionais, caracterizados em grande medida por condições mínimas 
de infraestrutura, correspondentes a um mínimo necessário para viabilizar a venda de suas unidades, acessadas via crédito e subsídios, por preços normalmente elevados e sustentados pelo Estado.

No caso das infraestruturas, Pirez (2012) identifica uma transição de um modelo centralizado-estatal para um modelo centralizado-privatizado a partir dos anos 1990. O Estado, assumindo predominantemente a função regulatória, passa a assegurar ganhos extraordinários a agentes privados por meio de processos de privatização, de formação de monopólios e oligopólios e de garantias tarifárias (PIREZ, 1999). Cumpre ressaltar que na base da compreensão desses processos de privatização está a mudança das relações de propriedade, flexibilizadas por meio de esquemas de concessões. As infraestruturas tornadas propriedades privadas serão exploradas também no sentido de obtenção de renda, a partir de apropriações imobiliárias, concebidas como receitas complementares. Parte desses avanços relaciona-se com o aprimoramento dos marcos regulatórios, que são transformados no sentido de assegurar maior segurança jurídica dos negócios e diversificar as estratégias de remuneração e exploração do espaço. As Parcerias-Público-Privadas (PPPs) desenhadas e regulamentadas em múltiplos formatos torna-se a ideia força do receituário neoliberal dos bancos e agências multilaterais de desenvolvimento, que passam a ser apropriadas por governos de distintas matrizes ideológicas.

A reconhecida elevação da qualidade do espaço urbano proveniente desses processos conduzidos por empresas cada vez mais capitalizadas é sobreposta a um tecido urbano historicamente marcado por precariedades e tende a exacerbar a diferenciação dos espaços urbanos. A diferenciação urbana e a acelerada transformação espacial envolvidas nesses processos parecem emergir como aspectos essenciais na ampliação dos ganhos para essas empresas. Muitos desses ganhos irão concretizar-se pela ampliação dos processos de capitalização da renda realizados pela ampliação dos preços dos imóveis.

O papel do Estado é parte decisiva para o reconhecimento de especificidades que esses processos adquirem na América Latina, tornando-se chave para formulação de alternativas políticas que realmente dialoguem com os desafios postos. $\mathrm{O}$ debate mais geral sobre o caráter dessas transformações aponta um importante avanço do Estado no sentido de implementar políticas que incrementam a captura do fundo público, da renda imobiliária e da provisão de habitação como solução econômica, distanciando-a de sua finalidade social

A disponibilidade de grande quantidade de financiamentos subsidiados, legitimada pela grande demanda habitacional pelos mais pobres, torna-se condição inicial para a inserção de investimentos globais a procura de retornos rápidos, elevados e seguros. Ao mesmo tempo, tomam força crescente projetos de renovação e reestruturação urbana, onde cada vez mais se dissemina a estratégia de produção de infraestruturas a partir da captura com ganhos imobiliários.

A percepção desses processos de incremento de captura de renda pelo Estado permite unificar esforços de pesquisas muitas vezes fragmentados por estudos que ora focam a habitação por meio de seus Programas Habitacionais, ora enfocam o Planejamento Urbano, por meio de estratégias urbanísticas. 
5 Pode ser citado como exemplo, o aumento do trabalho informal como parte da cadeia de produção industrial ou como parte fundamental da circulação de mercadorias.

\section{Separação entre produção formal e informal}

Uma segunda separação que se constituiu, sobretudo, a partir dos anos 1970, foi a produção formal capitalista da habitação e a produção informal, caracterizada majoritariamente pela assim chamada "autoconstrução". Dessa separação veio a compreensão de que a solução de moradia dada pela população e, consequentemente, sua reprodução social, era um fenômeno dissociado de uma política e do processo de acumulação de capital.

Neste sentido, o trabalho de Mautner (1999) é um dos primeiros no Brasil a apontar a relação entre política habitacional e acumulação de capital. Segundo a autora, a trilogia "loteamento clandestino/casa própria/autoconstrução" dos anos 1970 foi uma política de incentivo ao processo de periferização, porém inconfessa, por se apoiar em ocupação irregular. Nos EUA, a trilogia "loteamento/casa própria/ indústria da construção", foi planejada como estratégia nacional, porém apoiada no mercado. Mautner (1999) aponta justamente que o valor autoproduzido pelas famílias nos loteamentos irregulares, após a segunda camada de urbanização propiciada pelo Estado por meio da produção de infraestrutura, é capturada pelo capital imobiliário na terceira camada, agora constituída de um bem imóvel infraestruturado e "formalizado". Há, portanto, uma captação do valor autoproduzido pelo capital imobiliário e também um processo espoliativo adjacente.

Na América Latina, a adoção de práticas formais e informais, regulares e irregulares, legais e ilegais se imiscuem em diversas dimensões da economia e da vida ${ }^{5}$. No caso da produção da habitação, em particular, e do espaço urbano, em geral, essa dissociação obscurece a compreensão sobre o trânsito ou os vasos comunicantes entre tais práticas e as situações intermediárias, assim como setores que se beneficiam de ambas as produções - a produção de loteamentos e a indústria de materiais de construção permeiam tanto a produção denominada como formal quanto a informal de moradia. Outra consequência é que se adota a legislação como referência para definir o se considera ilegal ou irregular no espaço urbano, ou seja, padrões elitistas frente a realidade social, fazendo com que a ilegalidade esteja frequente e de discriminatoriamente associada à população de baixa renda.

Pirez (2016 e neste número) procura escapar da separação formal e informal ao propor as noções de produção mercantil, produção não mercantil e produção desmercantilizada da urbanização. O autor identifica uma heterogeneidade de modalidades de produção e de consumo na urbanização latino-americana e denomina a "urbanização popular" como autoprodução, dentro da produção não mercantil. Contudo, na dinâmica urbana, o processo de mercantilização avança sobre as outras formas, transformando-as. Nesse sentido, a produção não mercantil coloca em perspectiva uma visão crítica sobre as formas de resistência popular nas cidades.

Como exemplos desses vasos comunicantes, é possível identificar, no Brasil em particular, um mercado de transações de imóveis em favelas com modus operandi muito semelhante ao mercado imobiliário considerado "formal", inclusive com a presença de agentes que desempenham funções de corretores, incorporadores e proprietários rentistas. Assim como, práticas ilegais podem estar presentes em canteiros de obras de grandes construtoras, atestadas pelas denúncias do Ministério do Trabalho sobre a presença de trabalho análogo à escravidão (SHIMBO, 2017). 
Vale destacar que hoje nem mesmo o crédito habitacional, como no programa brasileiro Minha Casa, Minha Vida, exige comprovação de renda proveniente apenas de trabalho formalizado. Também se difundiram créditos e microcréditos à pessoa física para população de baixa renda sem necessidade de comprovação de renda. Houve um aumento da bancarização dos setores populares, propiciando mais uma forma de penetração do mercado financeiro no cotidiano das famílias. Grosso modo, as famílias mais pobres acessam crédito de consumo de instituições comerciais não bancárias a taxas exorbitantes, para compras de materiais de construção, eletrodomésticos etc., promovendo uma inclusão financeira, mas com alto grau de segregação econômica, ou aquilo que poderíamos denominar como uma "integração espoliativa" da população pobre.

\section{Invisibilidade da natureza na produção imobiliária e de infraestruturas}

Com um olhar retrospectivo sobre os estudos que tratam da produção imobiliária e de infraestrutura, ainda considerados como campos separados e sob a lógica da produção industrial, e também sobre os estudos sobre a urbanização, nota-se que as múltiplas dimensões do problema da natureza no processo de produção e reprodução do espaço urbano é um dos aspectos pouco trabalhados, e que pesquisas recentes buscam abordar.

Destacamos duas questões centrais nesse sentido. A primeira, se refere a compreensão do problema da natureza enquanto propriedade privada e as formas de exploração, extração e captação de rendas que derivam dessa relação na urbanização e, mais especificamente, na produção imobiliária sob o domínio das finanças. A segunda, reside na crítica sobre as narrativas contemporâneas da chamada questão ambiental, que tem pautado debates, políticas estatais e investimentos, em grande medida sem abalar as relações sociais que geram as degradações da natureza, as desigualdades e as precariedades socioterritoriais. A apropriação do discurso da sustentabilidade e da responsabilidade ambiental tem sido utilizado por diversos agentes públicos e privados como mais um ingrediente de valorização de projetos urbanos, ocultando os problemas decorrentes da apropriação da natureza na urbanização contemporânea.

Um ponto de partida para se entender a "ausência" da natureza (como condição material de reprodução da vida) decorre, como formulado por Lefebvre (1999), da instrumentalização do espaço na urbanização sob o capitalismo industrial, que degradou a natureza enquanto fornecedora de valores de usos gratuitos e necessários para a reprodução da vida. Pode-se dizer que, assim como o espaço foi instrumentalizado, o mesmo ocorreu com a natureza (natureza primeira, fundamento da ação humana sobre o espaço) para o processo de acumulação do capital. No metabolismo urbano industrial, e do ponto de vista econômico, a natureza é reduzida a recurso natural, e os efeitos negativos de sua destruição são considerados como algo externo ao processo produtivo, sendo socializados. Na construção da cidade capitalista a natureza é recriada e reaparece como símbolo, fragmento (em lotes, ou os espaços verdes) ou como representação. Apesar da transformação da natureza resultar do processo social, a ideia de oposição cidade e natureza manteve o consenso de uma noção mistificada da natureza como exterior à essas relações, e à própria produção da cidade. 
Ao mesmo tempo, à luz da crítica à economia política, a relação sociedade e natureza pode ser compreendida em outros termos pois, no capitalismo, a apropriação da natureza enquanto recurso se dá privadamente e é garantida por relações de propriedade (por meio de título jurídico), que estabelecem o domínio sobre parcelas do planeta. A propriedade privada da terra garante a exploração de um duplo monopólio, ou seja, o monopólio da exploração e o monopólio da renda, que permite captar uma valorização produzida socialmente e, também, atribuir preço a algo que não é produzido pelo trabalho e que seria um bem comum, como os elementos naturais. Na produção imobiliária e de infraestruturas essas condições estão reunidas no produto imobiliário que implicam na construção ou reconstrução de uma localização, o que depende da existência das infraestruturas.

Contudo, a relações sociais de propriedade são naturalizadas na sociedade em geral, o que sustenta e reitera a condição de desigualdade permanente e necessária para que o espaço lucrativo e rentista se reproduza. Para se repensar a relação entre sociedade e natureza, portanto, seria necessário desnaturalizar as relações sociais de propriedade.

Os estudos urbanos críticos, de certa forma e por muito tempo, deixaram de lado o problema da natureza, ou melhor, da produção da natureza como elaborado por Neil Smith (1988), o que também pode ser percebido pela desconsideração da ecologia pela crítica à urbanização capitalista ou pelo processo geral de reprodução do capital (CHESNAIS; SERFATI, 2003). As formas precárias de reprodução da vida têm se ampliado, afetando a coletividade como um todo, mas, particularmente, tem piorado as formas de espoliação e as condições de vida de grande parte da população urbana. Assim, ao mesmo tempo em que é preciso desnaturalizar as relações de propriedade, não se pode deixar de lado a natureza.

Por outro lado, a "questão ambiental" nunca esteve tão forte e presente e a preocupação com o meio ambiente parece prevalecer sobre uma crítica mais aprofundada. A construção da narrativa da sustentabilidade, ainda que seja uma noção em disputa por diferentes grupos e interesses, é facilmente apropriada aos interesses imobiliários no sentido de conciliar a ideia de desenvolvimento econômico com práticas de baixo impacto ou até mesmo de recuperação ambiental. Nesse sentido, a representação da natureza também passa a cumprir um papel nos projetos urbanos afastando-se das possibilidades concretas de usufruto dos espaços pela coletividade.

A flexibilidade do discurso ambiental tem justificado e auxiliado a realização de intervenções urbanísticas e de grandes projetos urbanos que promovem remoções de favelas situadas em margens de córregos, ou de moradias precárias em áreas de interesse do mercado imobiliário, e simultaneamente aumentam as ocupações de edifícios abandonados e a expansão periférica sobre áreas de proteção ambiental, como as áreas de mananciais. Os espaços de moradia precária são a alternativa de permanência dos pobres nas cidades, mas se trata de uma permanência sob permanente ameaça. A mercantilização da natureza também é evidente no acesso à água e ao saneamento, pois o acesso esse bem essencial está condicionado à regularidade de propriedade privada e à "solvência" da população, e que na configuração mais recente das companhias de saneamento, drenam os lucros do serviço público para acionistas. Os problemas de poluição do ar, do solo e das águas, também parecem que somente serão resolvidos se tornados mercadorias, ou precificados, alimentando 
a crença nas soluções via mercado. Esses exemplos, dentre outros que poderiam ser citados, nos fazem problematizar as abordagens hegemônicas da questão ambiental urbana, e repensar tanto as formas de representação da natureza como, sob uma lente crítica da produção da cidade, a apropriação da natureza no processo de acumulação do capital. Essa interpretação está, portanto, associada à produção imobiliária e de infraestruturas considerando ainda as particularidades da predominância do capital financeiro na produção do urbano.

\section{Elementos para a construção de uma agenda de pesquisa}

\section{Avançar na compreensão dos nexos entre imobiliário e financeiro}

$\mathrm{Na}$ análise articulada entre imobiliário e infraestrutura o que parece importante ser percebido é a crescente relevância da propriedade privada nos negócios de infraestrutura e a ascendente captura do fundo público no imobiliário. Envolvendo variadas formas de renda que se concretizam em diferentes escalas da reprodução do capital, essa perspectiva de análise exige a compreensão de articulação de processos imediatos e globais e uma trama de agentes.

Assim, do ponto de vista teórico-metodológico, nosso argumento é que se torna fundamental pensar os nexos entre infraestrutura e edificações considerando a própria unidade que o imobiliário propicia, na medida em que ele está em ambos os objetos e os atravessa.

Tal aproximação, não exime o pesquisador de observar os aspectos que permanecem diferenciados nesses dois setores. As frações de classes tradicionalmente envolvidas em cada um deles permanecem com aspectos diferenciados nas variadas formações nacionais, aspecto que parece ser fundamental para compreender a força e as particularidades de inserção do capital financeiro internacional em determinados contextos e projetos. Outra categoria chave na interpretação das atuais tendências de financeirização e privatização da produção do espaço são os proprietários de terra e sua constituição histórica em cada país da América Latina. A relevância e poder dessa classe na urbanização latino americana tende a torna-se ainda mais relevante na atualidade.

Ao mesmo tempo, cumpre observar que no curso da aproximação desses dois ramos com processos de acumulação financeira, aspectos que antes diferenciavam claramente a produção de infraestruturas e do imobiliário, como as formas de financiamento e as relações de propriedade, passam a ter cada vez mais características similares. A separação e diferenciação nítida entre a produção de infraestruturas e imobiliário sob uma perspectiva de domínio da acumulação industrial parece progressivamente se dissolver sob o domínio do capital financeiro. Essa dissolução não torna menos importante os esforços de perceber os distintos interesses de classes e formas de distribuição de riqueza.

A infraestrutura posta como condição geral à reprodução do capital e da força de trabalho, dentro da racionalidade industrial, reaparecerá nos processos contemporâneos de produção do espaço como meio de ampliação da captura de renda, seja nos imóveis, por aprofundar a diferenciação espacial característica das cidades latino-americanas 
6 Observação de Priscilla Connolly durante uma das sessões dos grupos de trabalho. concretizadas no aumento do preço das edificações, seja nas próprias infraestruturas, tornadas ativos em processos violentos de privatização. São esses insights que fortalecem a compreensão desses nexos entre imobiliário e infraestrutura, tendo a categoria da renda como aspecto central.

A centralidade da renda não pode, entretanto, obscurecer a permanência e relevância da exploração e espoliação, processos que a sustentam e tornam-se cada vez mais relevantes na continuidade do domínio financeiro, exacerbando-se no contexto latinoamericano. Apesar da dominância financeira encobrir a centralidade da produção, a renda se ancora na produção, imediata e global.

No esforço de ampliar a compreensão das transformações na produção das cidades latino- americanas, parece importante identificar de que modo os vasos comunicantes entre imobiliário e infraestrutura tem configurado a reestruturação de setores da metrópole, sendo que a infraestrutura "atualiza" o território criando novas frentes de atuação para incorporadores, tanto em áreas já consolidadas recriando espaços, as chamadas renovações urbanas, quanto em novas fronteiras na borda da metrópole, ampliada de maneira fragmentada. Essas atividades têm se intensificado e gerado mudanças urbanas e territoriais amplas, pois estão cada vez mais articuladas tanto do ponto de vista espacial, como em relação a associação de agentes públicos e privados. Isso coloca novos desafios para o planejamento territorial, para as formas de financiamento das intervenções urbanas e da política pública e para as possibilidades de enfrentamento das desigualdades socioespaciais.

O alcance de um novo patamar de investimentos na produção do espaço no contexto latino-americano, se por um lado nos colocou o desafio de ampliar a compreensão dos nexos entre imobiliário e infraestrutura, nos remete a atualizar as categorias da economia política na produção do espaço, entendendo o espaço como parte dessa lógica de acumulação, e a centralidade desses mecanismos na ampliação das desigualdades. É nesse sentido que poderíamos olhar para nossa realidade como sendo a hegemônica, pois a realidade dos países centrais vem se aproximando de muito de nossa realidade ${ }^{6}$.

\section{Enfatizar a dimensão imediata da produção, articulada à políti- ca e ao espaço}

A abordagem da economia política que se debruça sobre a produção imediata, ou seja, da construção em si imobiliária e da infraestrutura requisita uma perspectiva teórica e ferramentas metodológicas que capturem os trânsitos entre decisões e práticas dos agentes que financiam, que são proprietários, que constroem e que utilizam o ambiente construído como espaço de produção e ou de reprodução social. Neste sentido, procurando capturar essa mútua influência entre produção imediata e produção global do espaço, há algumas questões, categorias de análise e problemaschave para uma agenda de pesquisa sobre o tema.

O primeiro problema-chave que se coloca é o financiamento da produção de infraestrutura e de edificações. Torna-se importante compreender o financiamento da produção de edificações e da infraestrutura no contexto contemporâneo em que o imobiliário e o financeiro colocam um novo filtro que articula tais produções e, ao mesmo tempo, as alteram. 
Neste sentido, a análise sobre o fluxo e a origem dos recursos financeiros pode ser um ponto de partida, ao procurar identificar quem são as instituições que financiam e como financiam. Por exemplo, os investimentos em infraestrutura no Brasil eram financiados, em grande medida, por fundos públicos ou de regulação pública (FAT e FGTS) e ofertados por bancos públicos às empreiteiras (BNDES). Hoje há as concessões urbanísticas e as PPPs em que se alteram as práticas de produção da infraestrutura na medida em que o pagamento para serviços entra como custeio e não como investimento.

Uma outra questão diz respeito à regulação e ao modo como se aplicam impostos sobre os produtos e os serviços ligados à construção e à produção imobiliária, desde os insumos da construção civil até a aquisição dos imóveis. Considerando que até os anos 1980, a indústria da construção era ainda um dos poucos setores totalmente nacionalizado, principalmente no Brasil, e que hoje a internacionalização da economia e, em grande medida, a regularização do solo urbano (considerando a discussão de Mautner, 1999) propiciaram a vinda tanto de fornecedores de materiais e de equipamentos quanto de incorporadoras estrangeiros, é fundamental compreender a regulação e o pagamento de tais tributos numa escala que atravessa territórios nacionais.

Uma última questão sobre o problema do financiamento se refere às arenas de decisão e processos orçamentários. Se até os anos 1980, prevalecia o financiamento estatal para infraestrutura por meio do endividamento do Estado, com os processos de privatização, atualmente há diversas modalidades de financiamento público com administração privada de serviços, bem como a entrada de fundos de investimento estrangeiros, resultando num obscurecimento sobre o lugar e os agentes que governam tal produção. Nesse sentido, a questão que se coloca, enfatizando-se o papel do Estado, é quem decide e como são decididos os orçamentos e financiamentos públicos para produção da infraestrutura e da habitação.

Alguns exemplos indicam um novo contexto para a articulação entre a produção imobiliária e de infraestruturas sob a prioridade das finanças, que podem acontecer por meio de associações entre capitais nacionais, mas tendem a cada vez mais extrapolar as fronteiras e se articular a capitais internacionais. A internacionalização de empresas de construção que, por serem sensíveis aos ciclos econômicos, buscam diversificar sua atuação geográfica, ou a diversificação da produção em diferentes produtos imobiliários, ou ainda atuando tanto na construção de edifícios como de infraestruturas. Ou seja, há novos arranjos e formas de atuação das empresas, que são orientadas pela lógica financeira.

Além disso, há que se compreender a atuação dos fundos imobiliários que estão voltados para a busca da diversificação de investimentos em produtos e da geopolítica dos investimentos e conectando agentes, mercados, rentabilidades, governos. Isso pode ser verificado nos fundos de pensão no Chile transformados pelas políticas neoliberais, que constituem um grande capital formado pelos trabalhadores e que são investidos globalmente. Muitos trabalhadores chilenos são proprietários de uma fração qualquer de um produto no Golfo Pérsico, ou de um hotel de luxo. Tem sentido ético que os trabalhadores chilenos (75\% do PIB do Chile) financiarem o desenvolvimento de outros países quando o próprio país tem tantas carências? Esses grandes fundos acabam criando mais concentração e desigualdades. 
Um segundo problema-chave é a relação entre trabalho e tecnologia na construção civil e como ele pode ser tratado considerando as diferentes formas de produção de edificações e de infraestrutura (autoprodução, produção doméstica e produção capitalista ou por incorporação). Há alguns níveis de análise que podem ser explorados nessa perspectiva. O primeiro reside no setor, ou seja, como as empresas se organizam e estruturam um setor e quais são as estratégias por elas adotadas para atuar em cada negócio imobiliário ou de infraestrutura. O segundo está na dimensão imediata da produção, procurando identificar, por um lado, os processos de exploração, de superexploração e de espoliação de trabalhadores e, por outro, a transferência de valor entre esses processos. A exploração do trabalho pode ocorrer desde os trabalhadores mais precarizados (em geral, subempreitados para os serviços básicos de obras) até os trabalhadores qualificados (também subcontratados, por exemplo, para os serviços de projetos), tanto na produção doméstica quanto capitalista. Além disso, esses trabalhadores também se tornam espoliados na medida em que se combinam processos de endividamento, ao se adquirir bens de consumo (como a habitação) e se pagar serviços urbanos cada vez mais caros e por meio de financiamentos individuais. Dessa forma, é importante indagar, numa perspectiva contra-hegemônica, se há resistências nesses processos.

Por fim, o terceiro problema-chave se refere às alterações estruturais que houve em relação à propriedade, tanto da terra quanto dos ganhos (renda, lucro e juros) presentes hoje na produção, na gestão e nos serviços de infraestrutura e edificações. Um fenômeno comum aos países da América Latina foi a concentração de capitais no setor da construção, que ocorreu de modo bastante acelerado. Entretanto, para além dessa tendência geral, a questão que se coloca é se há processos e regulações específicos em cada um dos países.

Em relação aos tipos de ganhos, é necessário abrir a "caixa preta" dos indicadores financeiros das empresas a fim de se identificar e mensurar cada tipo de ganho obtido com a produção de infraestrutura e de edificações. Ao final, a pergunta essencial é: quem ganhou com a elevação recente dos preços imobiliários?

\section{Inserir a produção da natureza na compreensão do espaço}

A produção imobiliária e de infraestruturas são objetos que possibilitam iluminar situações críticas, geradas por intervenções diretas (investimentos em projetos de diferentes portes e obras) ou indiretas (regulamentações e parcerias) do Estado e do setor privado sobre o espaço que, cada vez mais, convergem para o tratamento da cidade como negócio. Como parte desse "negócio", as prioridades sociais e a realização de políticas públicas territoriais que atenderiam a necessidades básicas da população, amparadas em direitos sociais, ficam em segundo plano e se reproduzem formas de espoliação. Um dos desafios metodológicos para se articular os variados aspectos constitutivos desse processo, bem como o resultado concreto de tais intervenções no espaço e suas implicações sociais e ambientais é justamente ter como ponto de partida das investigações o próprio espaço. Também, é preciso identificar práticas que escapam à instrumentalização do espaço, situações residuais que indicam possibilidades de transformação, que seriam componentes essenciais da pesquisa sobre o urbano na perspectiva de trilhar caminhos para sua transformação. 
O atual contexto da predominância do capital financeiro que atua no setor imobiliário e de infraestruturas coloca novas questões para a produção do espaço e da natureza no urbano, no sentido em que a capitalização da renda futura passa a ser o principal objetivo dos projetos urbanos. Para isso, os títulos de propriedade geram diferentes produtos financeiros e as formas de privatização se multiplicam e passam a vigorar, inclusive, sobre o que antes era considerado como externalidade negativa, abrindo novos mercados e tecnologias que visam minimização de impactos ambientais e precificação de elementos da natureza. A natureza como propriedade privada, como título jurídico de uma parcela do planeta, pode ser mobilizada pelo capital financeiro e, portanto, pode ser produzida em qualquer lugar - se torna móvel.

Outro desafio é entender as transformações no espaço e na natureza que são instrumentalizados para a reprodução do capital, e a articulação de escalas que se imbricam, ou seja, questionarmos como o capitalismo global influencia a produção local, particularmente na reestruturação de espaços urbanos que tendem a ser concebidos e produzidos não mais somente sob a lógica da produção industrial, mas para a captura de rendas sob o predomínio das finanças. Nesse sentido, para desvendar lógicas especulativas é necessário compreender a centralização do capital e sua ligação à terra no processo de produção da riqueza social.

A terra e a propriedade da terra são elementos centrais na pesquisa sobre a transformação da natureza na produção do espaço urbano e há múltiplas dimensões a esse respeito que nem sempre são consideradas nos estudos urbanos e no planejamento territorial. A terra enquanto espaço físico se transforma com a urbanização e é fragmentada por meio da definição jurídica da propriedade que garante o seu domínio e confere ao proprietário o poder sobre frações do espaço. Considerando que a terra (e a natureza) enquanto propriedade privada moderna possui um duplo monopólio, como formulado por Marx (1971, p. 888), caberia melhor compreender o papel da terra na produção global e imediata.

Por um lado, a terra enquanto natureza é local de intervenção, e também permite a exploração e extração de recursos para a construção quando possui atributos especiais, o que confere ao seu proprietário a extração de lucros suplementares na forma de renda. Nesse sentido, e em diálogo com a cadeia da construção civil elaborada do Lovera (2011), há uma possibilidade de se pesquisar, em diferentes escalas, de que modo a terra enquanto geradora de matérias-primas participa do circuito nacional e internacional da economia na cadeia da construção civil, desenvolvendo a ideia de extrativismo, além de ser o local onde ocorre a construção.

Ao mesmo tempo, a terra é monopólio privado, o que confere ao seu proprietário grande poder de extrair renda a partir da apropriação privada da produção social do espaço urbano. No sentido de desnaturalizar as relações sociais de propriedade, como tratado anteriormente, uma agenda de pesquisa que vise identificar os vasos comunicantes entre a produção imobiliária e de infraestruturas poderia avançar na compreensão de como a natureza se insere no processo da captura da renda na produção imobiliária e de infraestruturas, por exemplo, buscando desvendar processos que são exteriores à construção, mas alteram o preço do terreno, mobilizando a propriedade. 
Considerando as particularidades da urbanização na América Latina, e a partir os conceitos formulado por Pedro Pirez, levanta-se a questão de compreender como a terra participa da urbanização mercantilizada, desmercantilizada e não mercantil, colocando em questão as possibilidades de produção de formas não mercantis de urbanização e, também, do uso da natureza.

No sentido da crítica da instrumentalização do espaço, também pode ser trabalhada a dimensão da terra e da natureza como bens comuns. Há países da América Latina que possuem a propriedade comum, que se diferencia da propriedade pública e estatal, tema pouco debatido do Brasil. Não se trata somente de uma questão jurídica, mas dos costumes de uso da terra, abrangendo outras dimensões culturais e políticas. Nesse sentido, abre-se uma agenda de pesquisa sobre os diferentes significados de Bem Comum na América Latina, as variadas formas de apropriação da terra no sentido de sua coletivização, e o olhar atento sobre os espaços residuais, que escapam da racionalidade econômica. Nesse sentido, a atuação dos movimentos sociais bem como a emergência de novas formas de resistência e luta urbana fazem parte da agenda de pesquisa.

\section{Considerações finais}

À guisa de conclusão, buscamos tecer como consideração final uma síntese do debate desenvolvido ao longo do texto, e que abre possiblidades para uma ampla agenda de pesquisa. O artigo buscou discutir questões emergentes para os estudos urbanos no contexto de transformação e reestruturação do capitalismo, com a predominância do capital financeiro. No urbano, esse processo reconfigura a trama de agentes, os desenhos de financiamento e os projetos, que passam a ser concebidos e executados para fomentar o ganho financeiro, atuando seletivamente sobre porções da metrópole, aprofundando desigualdades socioterritoriais. Para se interpretar esse processo, que abrange a produção imediata, global e total, é necessário repensar as concepções que antes explicavam o processo de urbanização regido pela lógica da acumulação industrial.

Outro aspecto que merece destaque é que essa reflexão foi construída a partir de um olhar latino-americano que visa entender, a partir das características desses países, como as cidades têm se transformado localmente como decorrência de um processo global. Nesse sentido, foram problematizados alguns conceitos presentes nos estudos urbanos e que hoje se mostram insuficientes e carentes de atualização, ou até mesmo se tornam obstáculos para a compreensão de processos em curso. Ao realizar essa crítica foram formuladas, ainda que de modo incipiente, questões de pesquisa sob um novo olhar.

A separação entre produção imobiliária e de infraestruturas como ramos distintos já não corresponde à realização de obras e projetos de intervenção urbana sob a lógica financeirizada, nos quais a configuração física é associada à uma modelagem financeira que "redesenha" setores da cidade, frequentemente amparados por instrumentos urbanísticos formulados pelo poder público. A presença de investidores internacionais, a ampliação dos processos de privatização e a captura dos fundos públicos por interesses privados são parte estruturante da financeirização do urbano na América Latina. Contudo, o funcionamento dos agentes e as formas de realização desses processos 
podem variar conforme os contextos locais, o que coloca em evidência uma relevante perspectiva comparada entre os países latino-americanos.

A concepção entre produção formal e informal, como partes individualizadas da produção da cidade, oculta os vasos comunicantes e as lógicas próprias que se criam nos contextos de construção da cidade, entre práticas consideradas legais e ilegais, reguladas e à margem da lei. Assim, outros referenciais teóricos precisam ser mobilizados para que se possa identificar e analisar tais processos.

Identificamos que o paradigma ambiental tão presente atualmente também oculta uma abordagem crítica sobre a transformação da natureza no processo de urbanização, o que não deve estar apartado do estudo da produção imobiliária e de infraestruturas. Nesse sentido, a terra enquanto materialidade e enquanto propriedade privada é fundamento para a compreensão da apropriação da natureza enquanto parte da instrumentalização do espaço no processo de acumulação no atual contexto.

Por fim, a agenda de pesquisa sobre produção imobiliária e de infraestruturas visa articular as dimensões imediata, global e total, e a construção de um pensamento crítico e propositivo contra-hegemônico.

\section{Referências bibliográficas}

AALBERS, M. The real estate/financial complex. Palestra. São Paulo: FAU/USP, 2015.

BOUGRAIN, F.; CARASSUS, J. Bâtiment: de l'innovation de produit a l'innovation de service. Paris: PUCA, 2003

CARASSUS, J. Économie de la filière construction. Paris: Presses de l'École Nationale des Ponts et Chaussées, 1987.

CHESNAIS, F. (org.). Finança Mundializada. São Paulo: Boitempo, 2005.

CHESNAIS, F.; SERFATI, C. Ecologia e condições físicas da reprodução social: alguns fios condutores marxistas. Crítica Marxista, 16, 39-75, 2003.

DARDOT, P.; LAVAL, C. A nova razão do mundo. Boitempo Editorial, 2017.

GITAHY, M. L. C.; PEREIRA, P. C. X. (orgs.). A construção habitacional em São Paulo na década de 1930. In: O complexo industrial da construção e a habitação econômica moderna 1930-1964. São Carlos: RiMa, 2002.

HARVEY, D. O trabalho, o capital e o conflito de classes em torno do ambiente construído nas sociedades capitalistas avançadas. Tradução de Flavio Villaça. Revista Espaço \& Debates Temas Urbanos e Regionais, São Paulo: Cortez, n 6, p. 6-35, 1982.

HARVEY, D. O Novo Imperialismo. 2. ed. São Paulo: Loyola, 2005.

HARVEY, D. O Neoliberalismo: história e implicações. São Paulo: Loyola, 2008.

LAPAVITSAS, C. The financialization of capitalism: 'Profiting without producing', City: analysis of urban trends, culture, theory, policy, action, 17:6, 792-805, 2013.

LEFEBVRE, H. Espaço e Política. Belo Horizonte, Editora UFMG, 2008.

LEFEBVRE, H. A revolução urbana. Belo Horizonte: UFMG, 1999. 
LENCIONI, S. Condições gerais de produção: um conceito a ser recuperado para a compreensão das desigualdades de desenvolvimento regional. In: Revista Electrónica de Geografía y Ciencias Sociales, Vol. XI, n. 245, ago. 2007.

LOVERA, Alberto. Radiografia de la indústria da construcción. El ciclo del capital. Caracas: UVC/EBUC, 2011.

LOVERA, A. El capital inmobiliario y constructor y la producción de la ciudad en América Latina. In: VELÁZQUEZ, Branca Rebeca Ramirez; PRADILHA, Emílio. (orgs). Teorías sobre la ciudad em América Latina. Ciudad de Mexico: Unidad Autonoma Metropolitana, 2014.

MARX, K. O Capital (Crítica da Economia Política). O processo global de produção capitalista. Livro 3, vol. 6., 1971.

PEREIRA, P. C. X., OSEKI, J., MAUTNER, Y. e MARICATO, E. Bibliografia sobre a indústria da construção: reflexão crítica. Sinopses. São Paulo: Faculdade de Arquitetura e Urbanismo. Universidade de São Paulo, v.16, p.36-45, dez.1991.

PEREIRA, P. C. X. Dinâmica imobiliária e Metropolização: a NOVA Lógica do crescimento urbano em São Paulo. Scripta Nova. Revista electrónica de geografía y ciencias sociales. Barcelona: Universidad de Barcelona, 1 de agosto de 2005, vol. IX, núm. 194 (10). <http://www.ub.es/ geocrit/sn/sn-194-10.htm> [ISSN: 1138-9788]

PEREIRA, P. C. X. Espaço, técnica e construção. Apropriação e produção do espaço: as implicações no desenvolvimento técnico da indústria da construção. O Caso da construção de moradias na cidade de São Paulo. Dissertação (Mestrado em Ciência Política). Universidade de São Paulo, São Paulo, 1984, 350 p.

PIREZ, P. Gestión de servicios y calidad urbana en la ciudad de Buenos Aires. EURE (Santiago), Santiago, v. 25, n. 76, p. 125-139, dic. 1999.

PIREZ, P. Servicios Urbanos y Urbanización en América Latina: su orientación entre el bienestar y la reestructuración. Geo UERJ - Ano 14, n. 23, v. 2, $2^{\circ}$ semestre de 2012 p. 793-824.

PIREZ, P. Las heterogéneas formas de producción y consumo de la urbanización latino-americana. Quid 16, n6, 2016, p. 131-167.

PROCHNIK, V. O macrocomplexo da construção civil. Rio de Janeiro: IEI/UFRJ, 1987.

RUFINO, M. B. C. Financeirização do Imobiliário e transformações na produção do espaço: especificidades da reprodução do capital e expansão recente na metrópole paulistana. In: FERREIRA, A.; RUA, J.; MATTOS, R. C. de (Orgs.) Metropolização: espaço, cotidiano e ação. Rio de Janeiro: Consequência, 2017.

SEABRA, O. C. de L. Os meandros dos rios nos meandros do Poder. Tietê e Pinheiros: valorização dos rios e das várzeas na cidade de Paulo. Tese de doutoramento. São Paulo: FFLCH/ USP, 1986.

SHIMBO, L. A forma de produção da habitação social de mercado no Brasil. In: CARDOSO, A., ARAGÃO, T., JAENISCH, S. (orgs). Vinte e dois anos de politica habitacional no Brasil: da euforia à crise. Rio de Janeiro: Letra Capital/Observatório das Metrópoles, 2017, p. 306-329.

SMITH, N. Desenvolvimento desigual. Rio de Janeiro: Bertrand Brasil S/A, 1988.

TOPALOV, C. Les Promoteurs immobiliers. Contribution à l'analyse de la production capitaliste du logement en France. Paris: Editora Mouton, 1974. 